\title{
EXPERIMENTAL ASSESSMENT OF SHEAR RESPONSE OF BRICK MASONRY RETROFITTED WITH TRM
}

\author{
LARISA GARCIA-RAMONDA ${ }^{1 *}$, LUCA PELÀ ${ }^{1}$, PERE ROCA $^{1}$ AND GUIDO \\ CAMATA ${ }^{2}$ \\ ${ }^{1}$ Department of Civil and Environmental Engineering \\ Universitat Politécnica de Catalunya (UPC-BarcelonaTech) \\ Jordi Girona 1-3, Campus Norte UPC, 08034 Barcelona, Spain \\ e-mail: larisa.garcia.ramonda@upc.edu, luca.pela@upc.edu, pere.roca.fabregat@upc.edu, \\ www.upc.edu $(*$ corresponding author $)$ \\ ${ }^{2}$ Department of Engineering and Geology \\ University "G. D' Annunzio" of Chieti Pescara \\ Viale Pindaro 42, I-65127 Pescara, Italy \\ e-mail:g.camata@unich.it,www.en.unich.it
}

Keywords: Masonry, TRM, FRCM, Cyclic shear-compression test, seismic retrofitting, "scucicuci" technique.

\begin{abstract}
As one of the main historical construction materials, masonry is abundant among the architectural heritage of earthquake-prone areas of the Mediterranean countries. Earthquake mitigation approaches are now focusing on strengthening solutions based on compatible and environmentally friendly repair materials. These solutions should efficiently improve the in-plane lateral strength and displacement capacity, which are the two most significant parameters considered in the seismic assessment of masonry buildings. This paper reports an experimental programme on masonry walls composed of handmade solid clay brick and hydraulic lime mortar, a recurrent typology for historical buildings. Tests under cyclic inplane forces were carried out on unreinforced and retrofitted walls. The unreinforced walls were repaired and retrofitted after being damaged in the first test and were then tested again to investigate the recovery of strength. The repair consisted in filling the open cracks and replacing the damaged bricks by following the so-called "scuci-cuci" technique. The retrofitting consisted of externally bonded textile reinforced mortar (TRM). The investigated TRM system was a continuous bidirectional grid of basalt embedded in hydraulic lime mortar. The experimental results show the suitability of the proposed solutions for seismic retrofit and post-earthquake repair of existing masonry buildings. The research results highlight the effectiveness of the investigated systems in increasing the resistance and ductility of unreinforced brick masonry. In addition, the results allow a better understanding of the behaviour of masonry walls subjected to cyclic horizontal displacement.
\end{abstract}

\section{INTRODUCTION}

Clay brick masonry is one of the most recurrent construction materials found in the 
Mediterranean built heritage. Owing to the material's almost null tensile strength, among other mechanical features, masonry buildings show large vulnerability to earthquake action. In an attempt to enhance the seismic performance of masonry constructions, a significant research effort has been undertaken during the last decades in order to validate efficient strengthening techniques. Among them, textile reinforced mortar (TRM) has been receiving increased attention due to its mechanical efficiency and satisfactory compatibility with the masonry substrate. This technique is also known in the scientific literature as FRCM (Fibre Reinforced Cementitious Matrix), according to the nomenclature adopted in the American standards [1]. As lime-based matrix is preferred to cementitious one nowadays, the acronym FRCM can be reinterpreted according to the novel definition "Fibre Reinforced Composites in inorganic Matrix" introduced by recent Italian standards CNR-DT 215/2018 [2].

In order to better understand the mechanical behaviour of TRM retrofitted masonry, a series of quasi-static experiments, consisting in shear-compression tests with cyclic loading, were carried out in the Laboratory of Materials and Structural Technology of the Universitat Politécnica de Catalunya (UPC-BarcelonaTech).

The main aim of the experimental programme was to investigate the in-plane performance of TRM strengthened brick masonry walls with focus on the predominant failure modes and deformation capacity. The programme comprised six tests on four walls. Two specimens were tested in the unreinforced configuration and later repaired and retrofitted with low-density basalt TRM (LDB-TRM). The remaining two walls were retrofitted with the same LDB-TRM solution. The walls were tested up to peak loading and beyond until an almost complete exhaustion of its residu collapse limit state. The and NTC2018 on limit states corresponding to Collapse (NC). The Italian standard NTC2018 which includes the Damage Limit State, and a Ultimate Limit State (SLU).
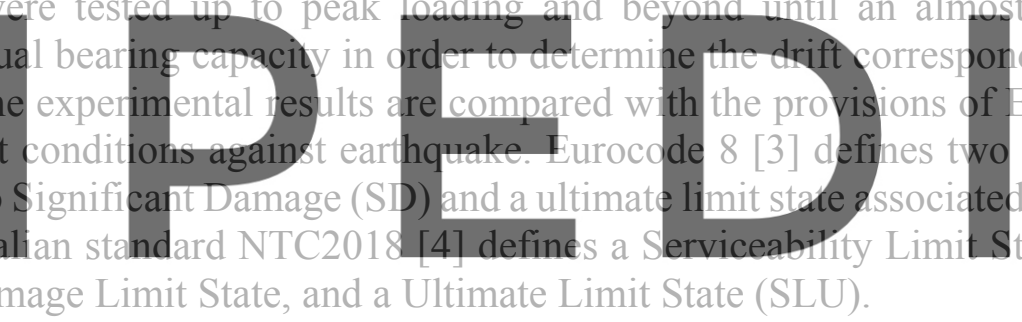
A for free at https//www.scipedia.com to download the version without the watermark 2 SPECIMENS FEATURES

\subsection{Material characterization}

Four masonry walls with dimensions $1270 \times 1270 \times 310 \mathrm{~mm}^{3}$ were built with clay bricks in Flemish bond with 21 courses and $15 \mathrm{~mm}$ thick mortar joints. The specimens represent one of the most frequent material combinations in historical masonry, i.e. solid clay brick and lime mortar joints. The handmade solid clay bricks were fired using traditional methods. The mortar was derived from a hydraulic lime-based commercial premix by reducing its compressive strength with limestone filler addition in order to replicate a low strength historical lime mortar [5]. The mechanical properties of the bricks and mortar were measured following standards EN 772-1 and EN 772-6 [6,7]. The measured normalized compressive strength $f_{b, c}$ and flexural strength $f_{b, f}$ of the bricks were equal to $17.99 \mathrm{MPa}$ (with coefficient of variation CV $8.3 \%$ ) and $2.44 \mathrm{MPa}(\mathrm{CV} 20.0 \%)$ respectively. The compressive strength $f_{m, c}$ and flexural strength $f_{m, f}$ of the mortar were equal to 2.61 MPa (CV 27.5\%) and 0.58 MPa (CV 28.4\%).

Two specimens were tested in the unreinforced configuration (URM), and later repaired and retrofitted with a bidirectional low-density basalt grid (LDB). The remaining two specimens 
were retrofitted with the same LDB. The textile was embedded in a mortar matrix consisting of a premixed NHL 3.5 natural hydraulic lime mortar with compressive strength $f_{m m, c}$ and flexural strength $f_{m m, f}$ equal to $13.18 \mathrm{MPa}(\mathrm{CV} 9.8 \%)$ and $3.26 \mathrm{MPa}(\mathrm{CV} 2.2 \%)$ respectively.

Four LDB sheets with dimensions of $800 \times 1270 \mathrm{~mm}^{2}$ were applied to each specimen. Two sheets were placed on each face of the wall with an overlap of $300 \mathrm{~mm}$ in the centre of the wall. The overlapping was chosen according to a previous study indicating that a minimum bond length of $200 \mathrm{~mm}$ is required for good performance [8]. The used LDB textile has a Young's Modulus of $90 \mathrm{GPa}$ and an ultimate tensile strength of $1700 \mathrm{MPa}$.

\subsection{Repair and retrofitting}

After the initial tests, two unreinforced specimens were repaired using the "scuci-cuci" technique, i.e. a local reconstruction of the damaged masonry portions based on fractured bricks replacement and lime mortar repointing. The aim of the repair was to restore the wall's structural continuity along the cracks and to recover its initial stiffness. The materials used for the scucicuci operation were the same ones utilized for the original construction in order to assure good compatibility in terms of stiffness and resistance. The considered repair technique followed three stages. First, the cracks of the specimens were widened using a rotary hammerdrill accessorized with a $20 \mathrm{~mm}$ width flat chisel, and a hand tool $30 \mathrm{~mm}$ width flat chisel. Second, the damaged bricks were replaced by new ones, as shown in Figure 1. Finally, the cracks were filled with the same lime-based mortar used for the retrofitting of the walls.
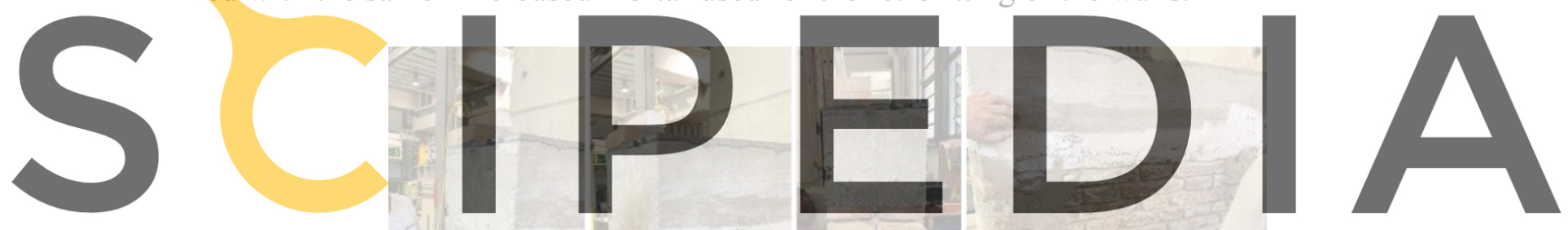

Register for free at https//www.scipedia.com to

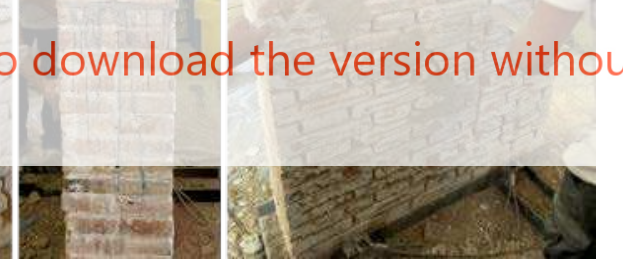

Figure 1: Scuci-cuci intervention on the URM tested walls. Removing and replacing of fractured units. Filling of cracks with lime-based mortar for repair.

\section{EXPERIMENTAL SET-UP}

The samples were laid on a metallic C-profile filled with concrete. This profile allowed the sliding shear failure to potentially occur in the bed joints of the lower course of bricks [9]. This profile was fixed on a stiff steel plate fixed to the strong floor slab of the laboratory by means of post-tensioned steel bars. In turn, a reinforced concrete (RC) beam was placed on top of the wall. This element was used for the application of both uniformly distributed vertical load and horizontal cyclic loading by the corresponding actuators. In addition, a stiff metallic H-profile stiffened with ribs was placed over the RC beam in order to ascertain an even distribution of the applied vertical loading. The vertical load was applied with two jacks with a capacity of $1000 \mathrm{kN}$ each. The jacks reacted against a stiff frame anchored to the strong floor. A $3 \mathrm{~mm}$ 
thick Teflon sheet and a $3 \mathrm{~mm}$ thick PVC sheet were inserted between the RC beam and the metallic profile to provide a smooth horizontal surface and to reduce the friction between both elements. In addition, a layer of cement-based mortar with thickness of 5 to $10 \mathrm{~mm}$ was placed between the RC beam and the PVC sheet in order to level the top surface of the beam and guarantee a uniform vertical load transfer.

\subsection{Testing procedure}

The shear compression tests were performed in two steps. First, the vertical force $V$ was gradually applied under force control. The valves of the jacks were closed once the designed compression stress was reached $\left(\sigma_{v}=0.3 \mathrm{MPa}\right)$. With the valves closed, no displacement or rotation of the top of the wall was possible and applying horizontal load induced a double bending condition [10]. Because of the testing mode, the vertical load increased with the application of horizontal load. The increase of vertical load depended upon the stiffness degradation of the wall.

The horizontal shear force $H$ was applied with a hydraulic actuator anchored to a reaction wall. The actuator had a pushing and pulling capacity of $350 \mathrm{kN}$ and $250 \mathrm{kN}$ respectively. Two steel plates $\left(530 \times 300 \times 30 \mathrm{~mm}^{3}\right)$ connected by 4 steel rods of $40 \mathrm{~mm}$ diameter were mounted aligned with the horizontal actuator. One of the plates was connected to the horizontal actuator by means of a hinge, enabling the application of reversed cyclic loading in the horizontal directions, see Figure 2.

The walls were instr measure diagonal displace its base. Eight potentioneter and vertical displacement. Finally, two displacement. The vertical load was measured b horizontal load by the actuator's inner load celt.

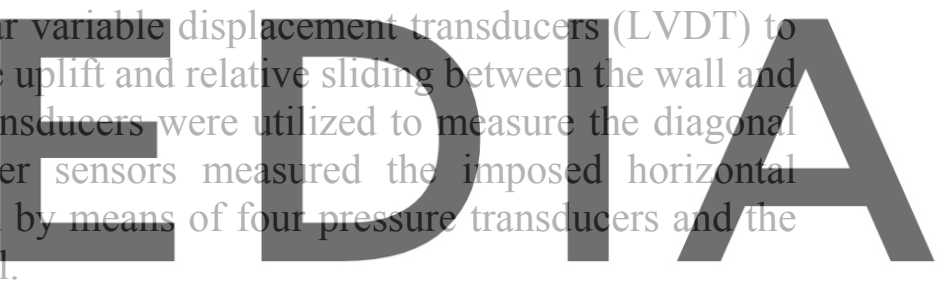

Register for free at https//www.scipedia.com to download the version without the watermark

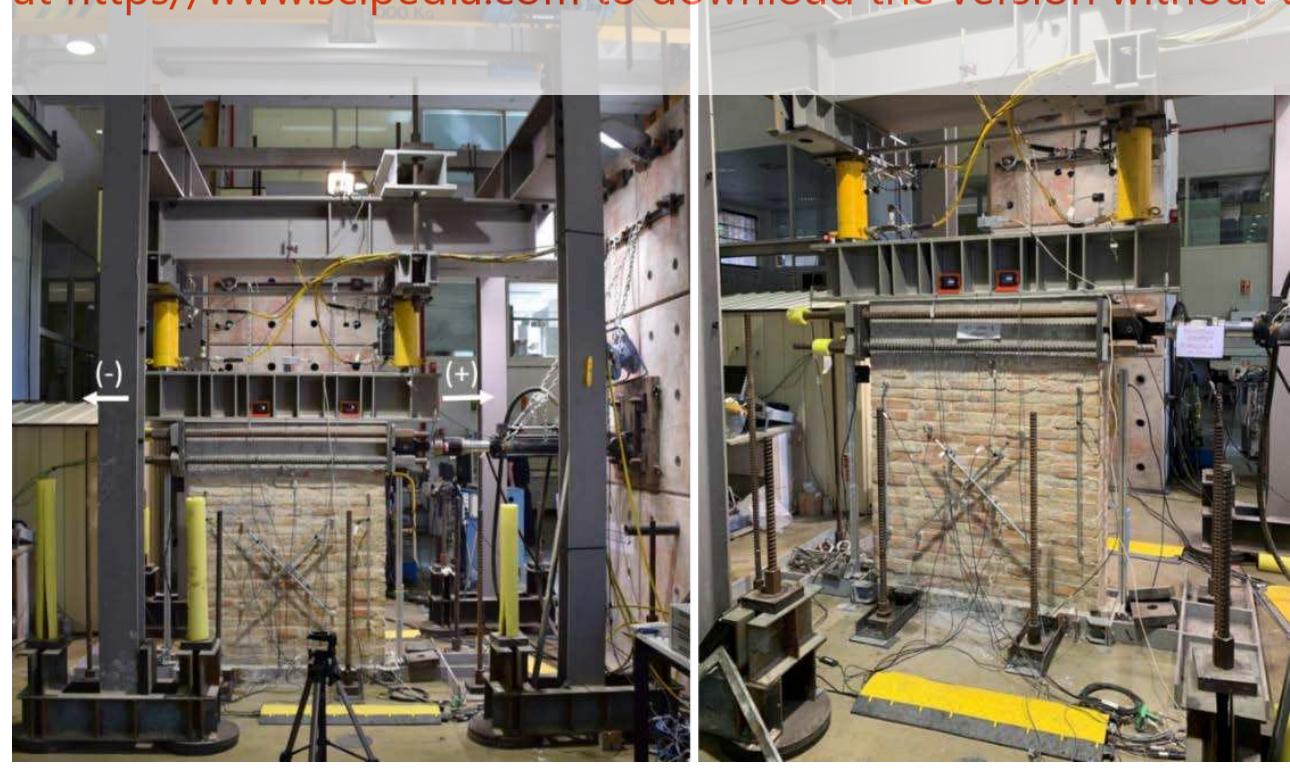

Figure 2: Set-up of the shear compression test 


\subsection{Loading protocol}

The in-plane cyclic loading was displacement-controlled to capture the accumulated damage in the wall and to enable the detection of the failure mechanism. The loading protocol adopted for all test, shown in Figure 3, follows the guidelines provided by FEMA 461 [11]. The loading history consisted of repeated cycles of step-wise increasing deformation amplitudes. Three cycles were completed for each amplitude.

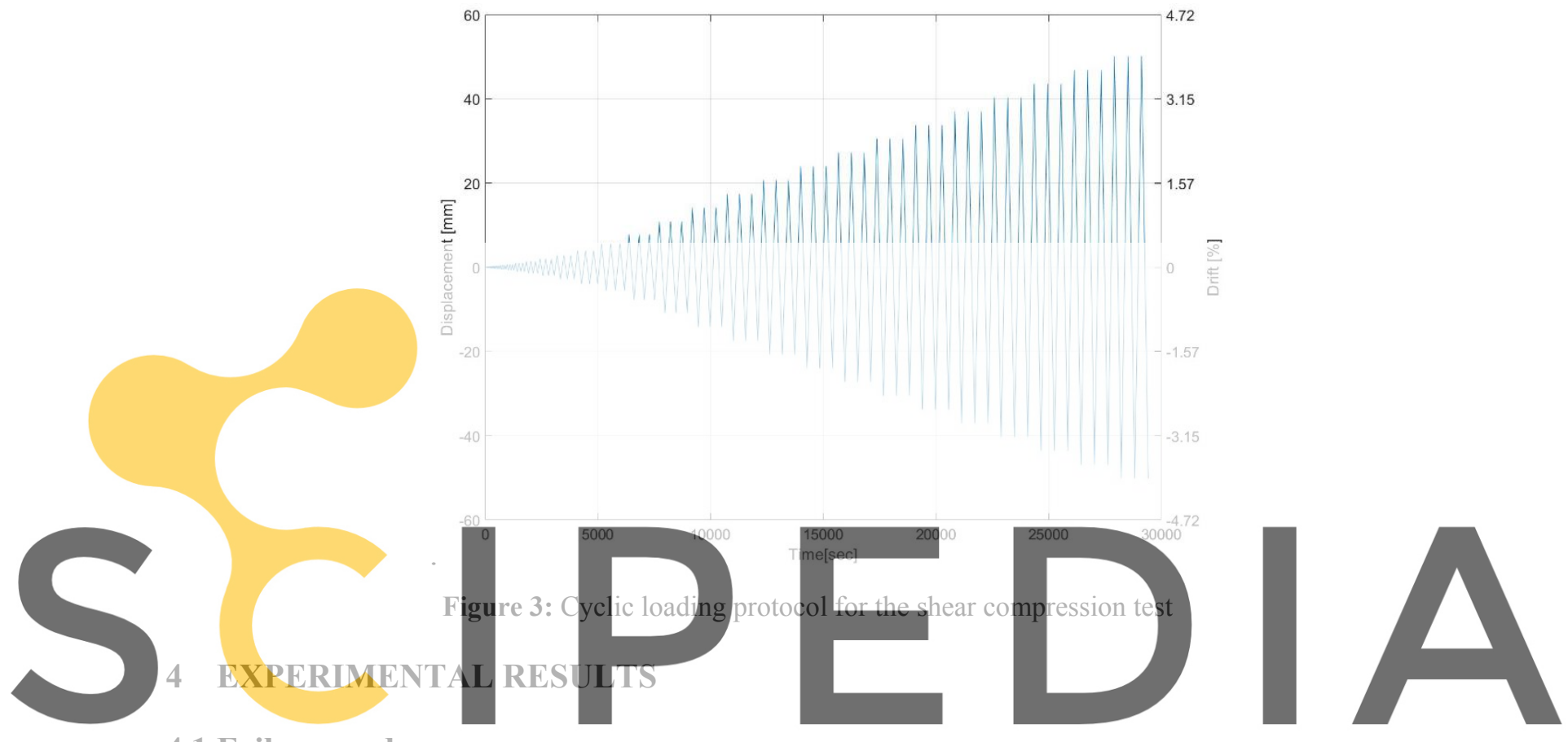

4.1 Failure modes

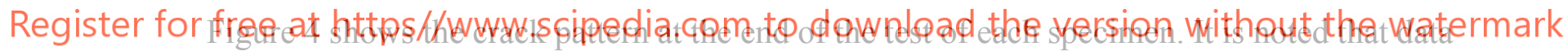

on specimen LDB-TRM (LDB_2) are disregarded due to technical problems experienced by

the loading system during this test.

The crack patterns evidence that all the specimens experienced shear failure. Damage in unreinforced specimens was characterised by a stair-step cracking mainly developed through the mortar joints and by tensile splitting of some units. The crack pattern of specimen URM_1 only shows one diagonal crack because the test was not continued beyond the development of this first crack. The load capacity of theses specimens shows significant scattering probably due to the variation of the mechanical properties of the masonry components.

The repaired and retrofitted specimens and the just retrofitted specimens showed also diagonal cracks developed from the centre of the panel with severe damage occurring in the region where the two cracks intersected.

The repaired and retrofitted specimens showed a more diffuse crack pattern in the centre of the panel compared to the just retrofitted one. The LDB grid in the former case had to withstand more displacement cycles, starting at early stages of the test, because of the re-opening of the repaired cracks. The cracks re-opening transferred the tensile stress to the LDB grid, causing the spalling of the mortar and thus the diffuse crack pattern. Despite this particular feature, the 
specimens retrofitted with LDB evidenced a more homogeneous response in terms of crack pattern and lateral load capacity compared with the unreinforced ones.

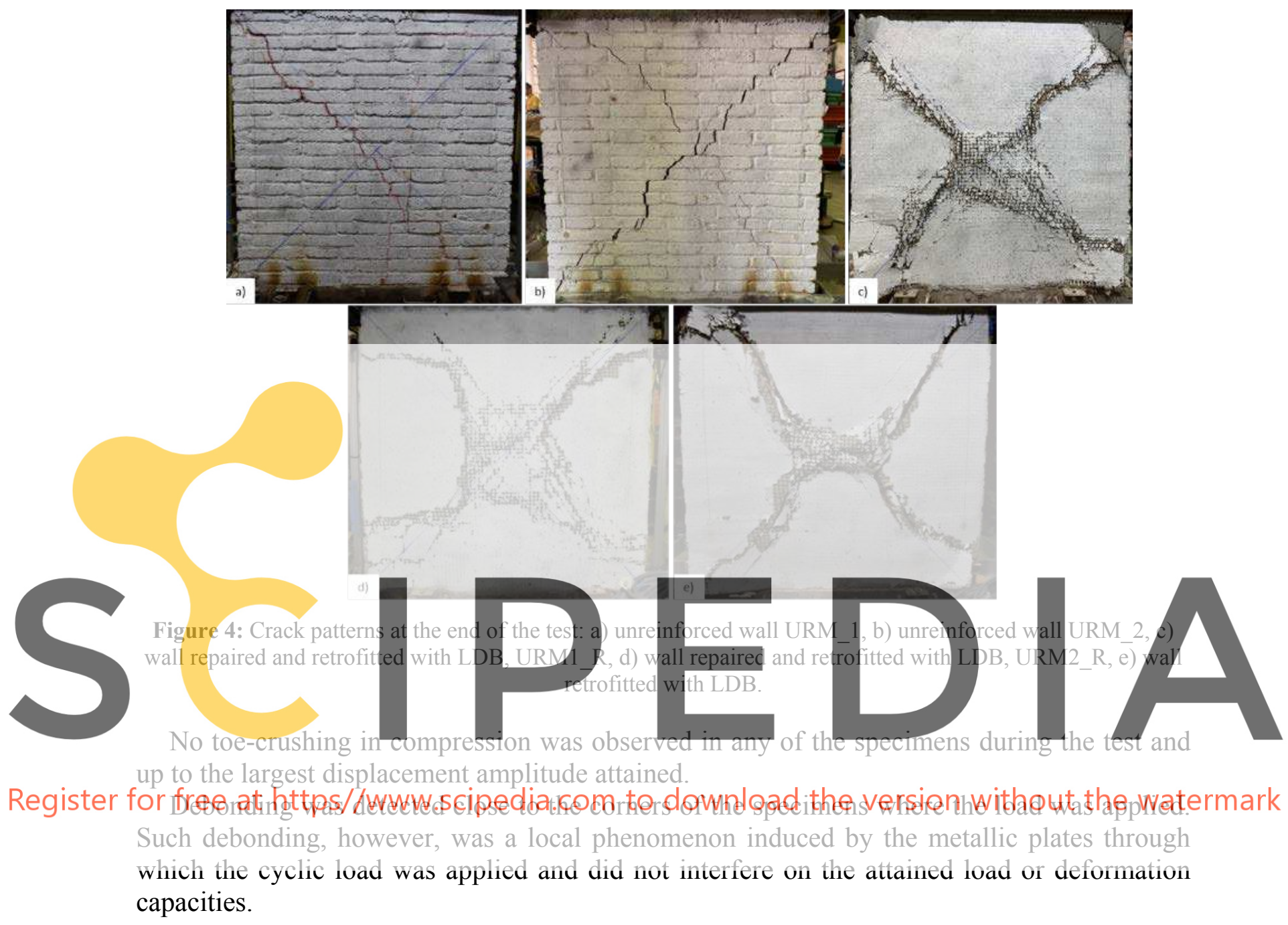

\subsection{Force-displacement curves}

Figure 5 shows the experimental force-displacement curves under cyclic in-plane loading. The experimental force-displacement envelopes are derived from the hysteretic curves and constructed by connecting the peak force at the first cycle of each displacement amplitude. The positive direction is the direction in which the horizontal hydraulic actuator pulls the specimen, whereas the negative one is the direction in which the actuator pushes the specimen ( Figure 2).

The experimental curves are characterized by an initial linear branch corresponding to the undamaged behaviour of the structure. At the onset of cracking, and with the development of damage and energy dissipation, the response becomes non-linear, as evidenced by the forcedisplacement envelope, while at the same time wider hysteretic loops are observed. The hysteretic loops widen progressively as the residual strength decreases until failure. Among the unreinforced specimens, the wider hysteretic loops were seen in URM_2 (see Figure $5 \mathrm{~b}$ ) in 
correspondence with the more severe damage observed in it during and after the test, Figure 4 b. However, and after repair and testing, the same specimen URM2_R showed a more ductile and progressive damage than its pair URM1_R.

The repaired and retrofitted walls showed a moderated improvement in lateral load-bearing capacity. However, the peak loads were reached at a larger displacement compared with the unreinforced ones. Consequently, their global behaviour showed larger deformation capacity and ductility, as seen in Figure 5. The just retrofitted specimens showed a significant increment in both lateral-load bearing and deformation capacity, evidencing the effectiveness of the reinforcement system.

Table 1 summarizes the main parameters of the force-displacement experimental curves for both directions. The cracking load $H_{c r}$ is the one recorded when the first cracks became visible. The peak load $H_{\max }$ is the one corresponding to the maximum lateral load attained. The ultimate load $H_{u}$ is derived from the bilinear idealization as discussed in the following section.

Table 1: Experimental first crack and peak loads. Ultimate load obtained for the bilinear idealization.

\begin{tabular}{|c|c|c|c|c|c|c|c|c|c|c|}
\hline \multirow{2}{*}{ Specimen } & \multicolumn{2}{|c|}{ First crack load [kN] } & \multicolumn{2}{|c|}{ Peak load [kN] } & \multicolumn{2}{|c|}{ Ultimate load [kN] } & \multicolumn{2}{|c|}{$\mathrm{H}_{\mathrm{cr}} / \mathrm{H}_{\max }$} & \multicolumn{2}{|c|}{$\mathrm{H}_{\mathrm{u}} / \mathrm{H}_{\max }(-)$} \\
\hline & $\mathrm{H}_{\mathrm{cr}}(-)$ & $\mathrm{H}_{\mathrm{cr}}(+)$ & $H_{\max }(-)$ & $\mathrm{H}_{\max }(+)$ & $\mathrm{H}_{\mathrm{u}}(-)$ & $\mathrm{H}_{\mathrm{u}}(+)$ & $(-)$ & $(+)$ & $(-)$ & $(+)$ \\
\hline URM_1 & -114.46 & - & -192.38 & 150.7 & -176.02 & - & 0.59 & - & 0.91 & - \\
\hline URM_2 & -102.31 & 104.96 & -162.29 & 151.56 & -154.22 & 146.37 & 0.63 & 0.69 & 0.95 & 0.97 \\
\hline URM1_R & -120.70 & 126.05 & -175.09 & 180.08 & -161.53 & 174.42 & 0.69 & 0.70 & 0.92 & 0.97 \\
\hline URM2_R & -142.20 & 132.44 & -194.56 & 167.88 & -181.99 & 162.87 & 0.73 & & 0.94 & 0.97 \\
\hline $\mathrm{LDB} \_1$ & -135.84 & 146.19 & -213.10 & 207.16 & -195.95 & 202.80 & 0.64 & & 0.92 & 0.98 \\
\hline
\end{tabular}

response of masonry walls. The idealization permits the determination of the response spectra

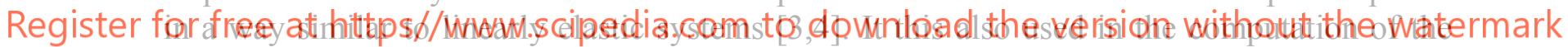
ductility [12].

The bilinear approximation of the experimental envelope curves was obtained as described in Figure 6. First, the cracking point was identified along with the peak load. The ultimate displacement $\delta_{u}$ was defined as the displacement at which the lateral strength had dropped to $80 \%$ of $H_{\max }$. If such a large drop was not attained, the largest displacement reached during the test was taken as $\delta_{u}$. The ultimate strength $H_{u}$ is defined as the maximum load o the bilinear idealization and is calculated taking into account the energy dissipation capacity of the experimental envelope curve. The ultimate strength is determined so as to produce a bilinear curve enveloping the same are below as the experimental curve up to $\delta_{u}$. For the present application, the bilinear idealization was calculated for both positive and negative directions. 

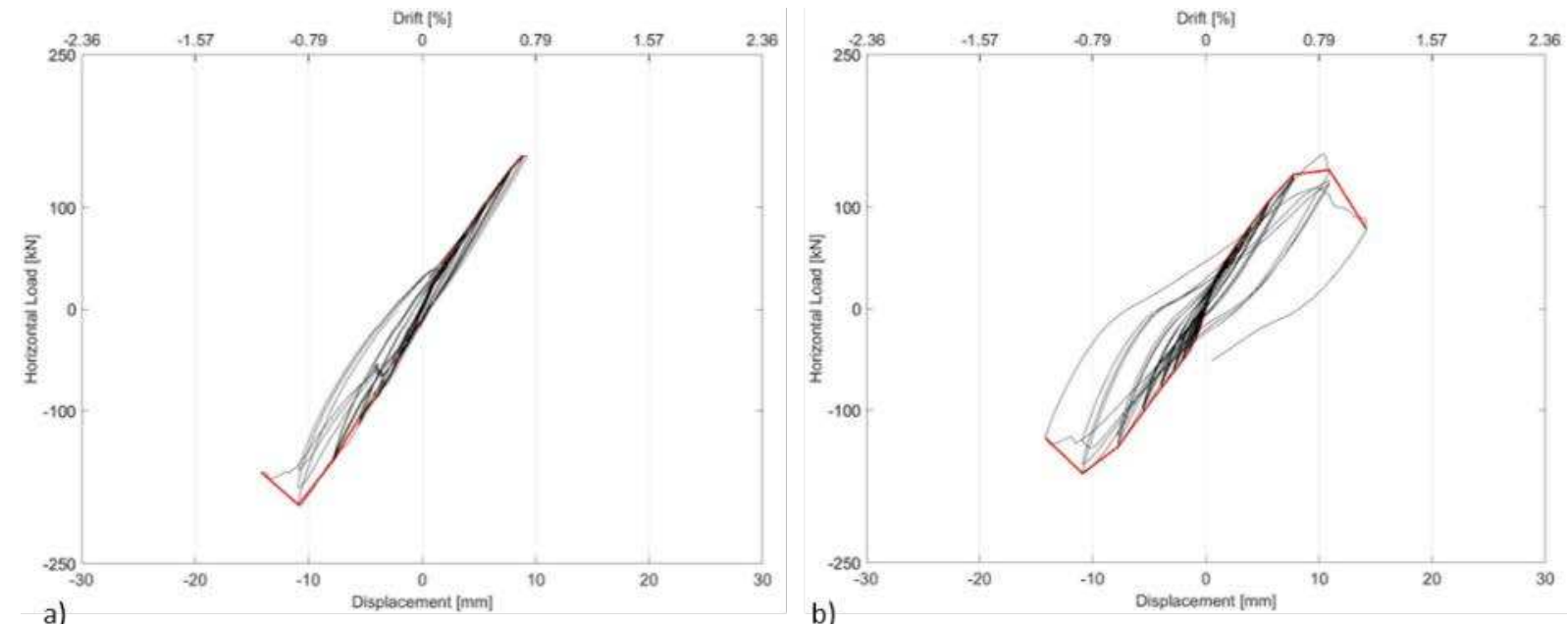

a)

b)

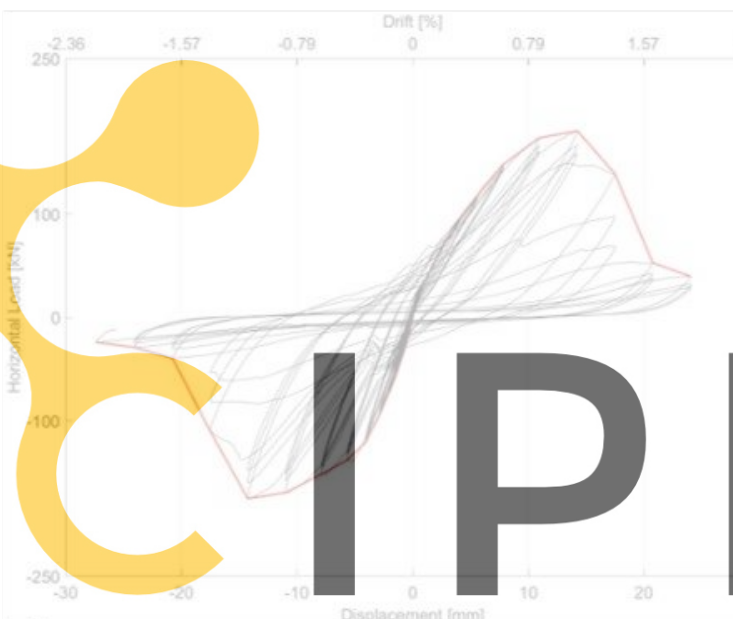

c)

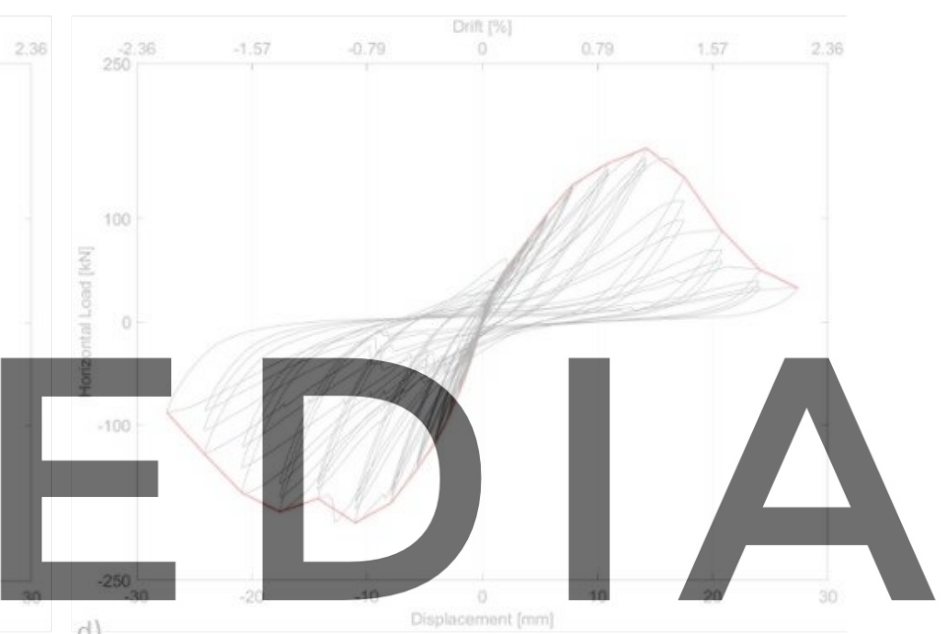

d)

Register for free at https//www.scipedia.com to download the version without the watermark

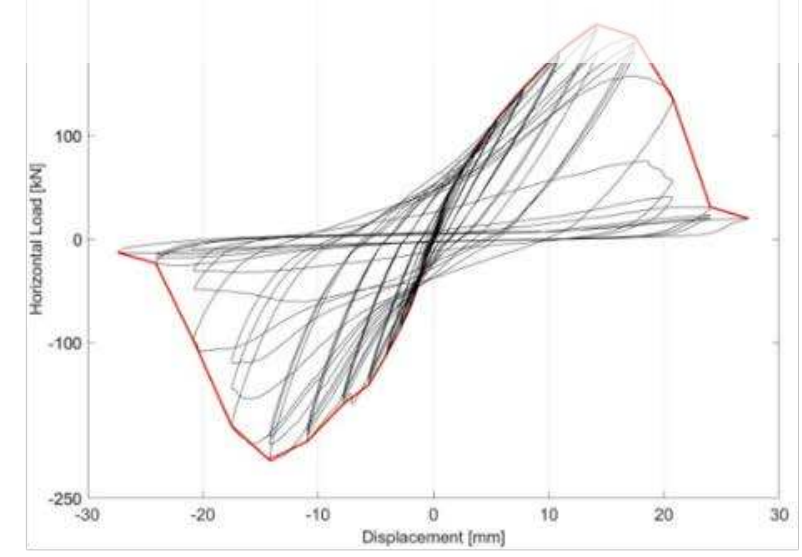

e)

Figure 5: Force-displacement hysteresis curves and envelope curves of tested walls: a) unreinforced wall URM_1, b) unreinforced wall URM_2, c) wall repaired and retrofitted with LDB, URM1_R, d) wall repaired and retrofitted with $\left.\mathrm{LDB}, \mathrm{URM} 2 \_\mathrm{R}, \mathrm{e}\right)$ wall retrofitted with LDB (LDB_ $\overline{1}$ ). 
Table 1 shows the ratio $H_{c r} / H_{\max }$ which on average is equal to 0.69 (CV 8\%). This value is consistent with Eurocode 8 [3] and the proposal of Tomaževič [13] and Magenes and Calvi [12] for the bilinear idealization of the hysteretic behaviour of the wall, which propose a $H_{c r} / H_{\max }$ value equal to 0.7 . However, the ratio $H_{u} / H_{\max }$ yields a higher value than 0.9 , which is the value proposed by the aforementioned authors. The value of the ratio for all the tests is on average equal to 0.95 (CV 3\%).

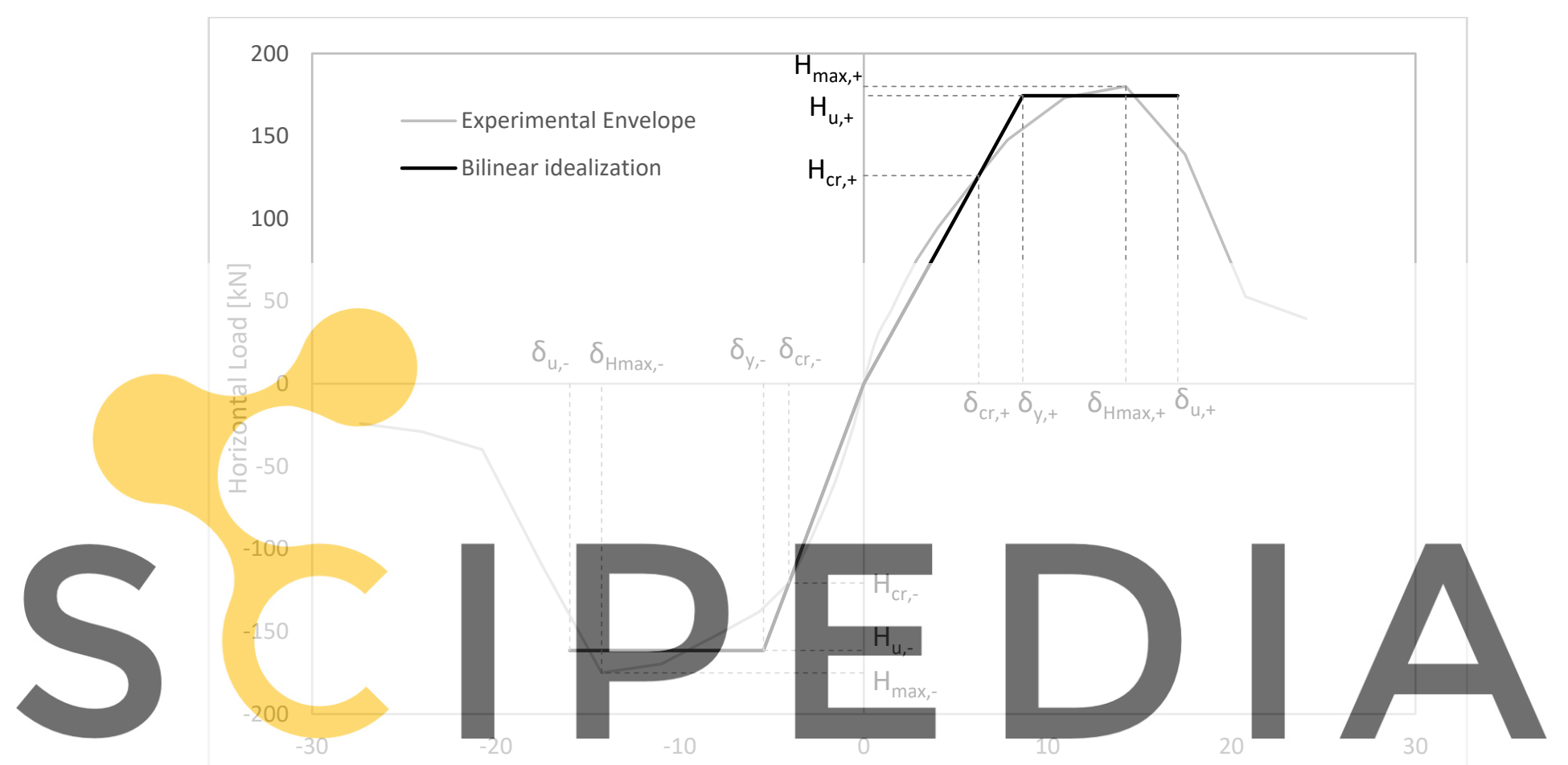

Register for free at https//www.scipedia.com to download the version without the watermark Figure 6: Example of bilinear idealization.

Table 2 and Table 3 show the main limit states analysed following [14,15] in terms of displacement and drift. The aforementioned authors considered five limit states. The displacement at cracking point $\delta_{c r}$ corresponds to the displacement for which a load equal to $70 \% H_{\max }$ is attained. The displacement at yielding $\delta_{y}$ is associated with the ultimate load $H_{u}$. The maximum displacement $\delta_{\text {Hmax }}$ corresponding to the peak load associated to the SD limit state defined by the codes. The ultimate displacement $\delta_{u}$ corresponds to the displacement for which the reduction of the lateral strength is $20 \%$ and is associated to the NC limit state introduced by the codes. In addition, $[14,15]$ defines a collapse displacement $\delta_{c}$ as the one corresponding to ta drop of the lateral strength of $50 \%$.

EC8 [3] defines two main limit states corresponding to Significant Damage (SD) and a ultimate limit state associated with Near Collapse (NC). For unreinforced masonry walls failing in shear mode, the limit drifts corresponding to the SD and NC states are set to $\theta_{S D}=0.4 \%$ and $\theta_{N C}=0.5 \%$ respectively. The Italian standard NTC2018 [4] defines a Ultimate Limit State (SLU), equivalent to EC8's NC state, for which the drift limitation is equal to $\theta_{S L U}=0.5 \%$.

When compared with the limit drifts defined by EC8 [3] and the Italian code [4], it is 
observed that both standards underestimate the deformation capacity of the unreinforced tested walls by $50 \%$. The average value of drift obtained in the experimental test, considering both directions, for the URM specimen for the SD and NC limit states are $0.8 \%$ and $1.1 \%$ respectively.

Table 2: Experimental displacements corresponding to different damage levels.

\begin{tabular}{|c|c|c|c|c|c|c|c|c|c|c|}
\hline \multirow[t]{2}{*}{ Specimen } & \multicolumn{2}{|c|}{$\begin{array}{l}\text { Cracking displ. } \\
{[\mathrm{mm}]}\end{array}$} & \multicolumn{2}{|c|}{$\begin{array}{l}\text { Yielding displ. } \\
\text { [mm] }\end{array}$} & \multicolumn{2}{|c|}{ Max displ. [mm] } & \multicolumn{2}{|c|}{$\begin{array}{l}\text { Ultimate displ. } \\
\text { [mm] }\end{array}$} & \multicolumn{2}{|c|}{$\begin{array}{c}\text { Collapse displ. } \\
\text { [mm] }\end{array}$} \\
\hline & $\delta_{\text {cr }}(-)$ & $\delta_{\mathrm{cr}}(+)$ & $\delta_{y}(-)$ & $\delta_{y}(+)$ & $\delta_{H \max }(-)$ & $\delta_{\text {Hax }}(+)$ & $\delta_{u}(-)$ & $\delta_{u}(+)$ & $\delta_{c}(-)$ & $\delta_{c}(+)$ \\
\hline URM_1 & -5.55 & - & -8.53 & - & -10.89 & 8.94 & -14.16 & - & -14.16 & - \\
\hline URM_2 & -5.56 & 5.51 & -8.38 & 7.68 & -10.90 & 10.91 & -13.95 & 12.26 & -14.18 & 14.17 \\
\hline URM1_R & -4.08 & 6.25 & -5.45 & 8.65 & -14.26 & 14.25 & -15.99 & 17.07 & -18.54 & 19.34 \\
\hline URM2_R & -5.62 & 7.82 & -7.19 & 9.62 & -11.01 & 14.23 & -21.71 & 17.86 & -26.59 & 21.75 \\
\hline LDB_1 & -5.61 & 7.81 & -8.09 & 10.83 & -14.22 & 14.17 & -17.89 & 19.1 & 20.46 & 21.75 \\
\hline
\end{tabular}

Table 3: Experimental drift values corresponding to different damage levels.

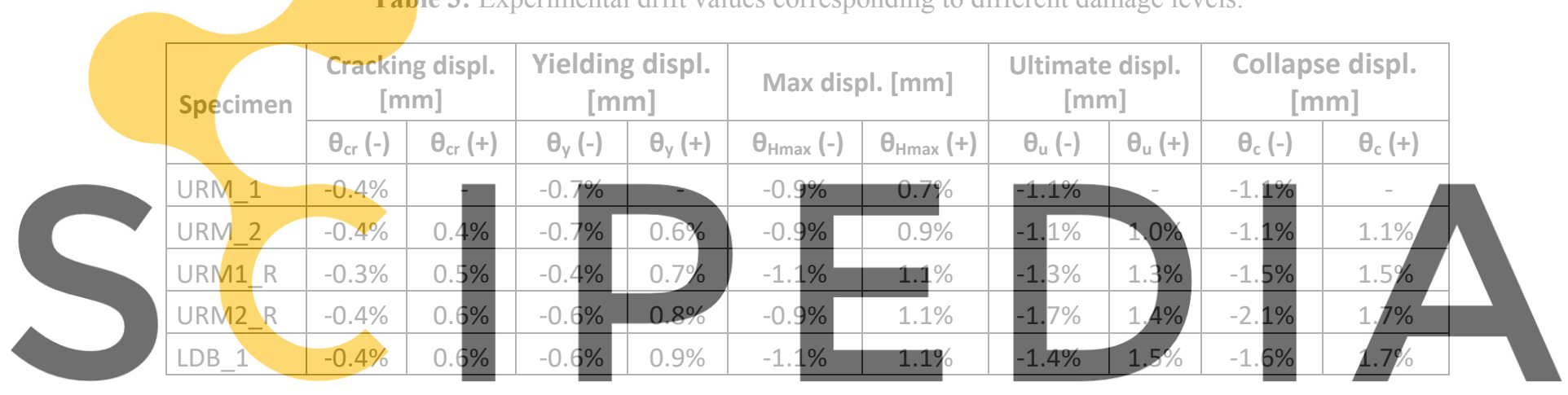

5 CONCLUSIONS

Register for free at https//Www.scipedia.com to download the version without the watermark The application of a bidirectional basalt grid (LDB) improved the in-plane response of the masonry walls in terms of load-bearing capacity and deformation capacity. When compared with the reference unreinforced ones, the retrofitted walls showed a significantly more ductile behavior with larger lateral displacement and consequently greater deformation capacity.

- The reinforced walls showed a more homogeneous response characterized by very similar crack patterns, failure modes and load capacities. By comparison, the unreinforced ones showed results that are more scattered in terms on lateral loadbearing capacity.

- The scuci-cuci and retrofitting intervention applied to the previously damaged walls, attained a satisfactory repair with full recovery of the initial load-bearing capacity.

- The application of the current codes has led to a significant underestimation of the deformation capacity shown by the tested walls. The underestimation is of $50 \%$ for the unreinforced walls. 
Acknowledgements. The authors gratefully acknowledge the financial support from the Ministry of Science, Innovation and Universities (MCIU) of the Spanish Government, the State Agency of Research (AEI) and the European Regional Development Fund (ERDF) through the SEVERUS project ("Multilevel evaluation of seismic vulnerability and risk mitigation of masonry buildings in resilient historical urban centres", ref. num. RTI2018-099589-BI00), and from Kerakoll Ibérica S.A. through the RTD project A-01217. Support from Secretaria d'Universitats i Investigació de la Generalitat de Catalunya through a predoctoral grant awarded to the first author is also gratefully acknowledged.

\section{REFERENCES}

[1] American Concrete Institute, ACI 549.4R-13 - Guide to Design and Construction of Externally Bonded Fabric-Reinforced Cementitious Matrix (FRCM) Systems for Repair and Strengthening Concrete and Masonry Structures, (2013).

[2] CNR - Consiglio Nazionale delle Ricerche, DT 215/2018 - Istruzioni per la progettazione, l'esecuzione ed il controllo di interventi di consolidamento statico mediante l'utilizzo di compositi fibrorinforzati a matrice inorganica (in Italian), (2018).

[3] European Standard, Eurocode 8 : Design of structures for earthquake resistance — Part 3: Assessment and retrofitting of buildings., 3 (2004).

[4] Ministero delle Infrastrutture e dei Trasporti, DM 17/01/2018 - Aggiornamento delle "Norme Tecniche per le Costruzioni" (in italian), (2018) 1-198.

[5] J. Segura, D. Aponte, L. Pelà, P. Roca, Influence of recycled limestone filler additions on the mechanical behaviour of commercial premixed hydraulic lime based mortars, Constr. Build. Mater. 238 (2020). doi:10.1016/j.conbuildmat.2019.117722.

[6] CEN, EN 772-1, Methods of test for masonry units. Part 1: Determination of compressive strength, Com. Eur. Norm. Brussels. (2011).

[7] CEN, EN 772-6, Methods of test for masonry units. Part 6: Determination of bending tensile strength of aggregate concrete masonry units., Com. Eur. Norm. Brussels. (2002).

[8] M. Santandrea, I.A.. Imohamed, C. Carloni, C. Mazzotti, S. de Miranda, F. Ubertini, A study of the debonding mechanism in steel and basalt FRCM masonry joints, Brick Block Mason. - Trends, Innov. Challenges. (2016) 433-440.

[9] C. Knox, Assessment of Perforated Unreinforced Masonry Walls Responding In Plane, The university of Auckland, 2012.

[10] G. Magenes, G.M. Calvi, Cyclic behaviour of brick masonry walls, in: Balkema (Ed.), Proc. Tenth World Conf. Earthq. Eng. 19-24 July 1992 Madrid, Spain, 1992: pp. 35173522.

[11] Applied Technology Council, Interim Testing Protocols for Determining the Seismic Performance Characteristics of Structural and Nonstructural Components - FEMA 461, (2007).

[12] G. Magenes, G.M. Calvi, In-plane seismic response of brick masonry walls, Earthq. Eng. Struct. Dyn. 26 (1997) 1091-1112.

[13] M. Tomaževič, Earthquake-Resistant Design of Masonry Buildings, Imperial Collage Press, 1999. doi:10.1142/9781848160835.

[14] F. Vanin, D. Zaganelli, A. Penna, K. Beyer, Estimates for the stiffness, strength and 
drift capacity of stone masonry walls based on 123 quasi-static cyclic tests reported in the literature, Bull. Earthq. Eng. 15 (2017) 5435-5479. doi:10.1007/s10518-017-01885.

[15] M. Godio, F. Vanin, S. Zhang, K. Beyer, Quasi-static shear-compression tests on stone masonry walls with plaster: Influence of load history and axial load ratio, Eng. Struct. 192 (2019) 264-278. doi:10.1016/j.engstruct.2019.04.041. 